\title{
Hospital treatment of severe acute exacerbation of chronic obstructive pulmonary disease in COVID-19 situation: back to basics
}

\author{
Pratap Upadhya ${ }^{1}$, Rohit Vadala ${ }^{2}$, Arpitha $\mathbf{A}^{3}$ \\ ${ }^{1}$ Department of Pulmonary Medicine, Jawaharlal Institute of Postgraduate Medical Education and Research, \\ Puducherry; ${ }^{2}$ Department of Pulmonary, Sleep and Critical Care Medicine, Metro Centre for Respiratory Diseases, \\ Metro Multispecialty Hospital, Noida; ${ }^{3}$ Department of Obstetrics and Gynecology, Jawaharlal Institute of Postgraduate \\ Medical Education and Research, Puducherry, India
}

\begin{abstract}
Patients of chronic obstructive pulmonary disease (COPD) during COVID-19 pandemic have higher morbidity. Treatment of these patients require aerosolization procedures like nebulization and noninvasive modalities for ventilation like non-invasive ventilation (NIV) and high flow nasal cannula (HFNC). Role of these procedures in corona virus transmission when treating a case of acute exacerbation of chronic obstructive pulmonary disease should be further studied.
\end{abstract}

To the Editor,

Chronic obstructive pulmonary disease (COPD) is a common respiratory condition due to airflow limitation with significant morbidity and mortality. Due to its chronicity, it is often characterized by frequent exacerbations requiring prolonged treatment. Patients with COPD are at higher risk for poorer outcomes due to coronavirus dis-

Correspondence: Pratap Upadhya, Department of Pulmonary Medicine, Jawaharlal Institute of Postgraduate Medical Education and Research, Old Ward Block, Puducherry, India.

Tel. +91.7087652869 .

E-mail:drpratapu@gmail.com

Key words: Chronic obstructive pulmonary disease; acute exacerbation; coronavirus; non-invasive ventilation; aerosol; high flow nasal cannula.

Contributions: All the authors contributed equally.

Conflict of interest: The authors declare no conflict of interest.

Funding: None

Received for publication: 2 June 2020.

Accepted for publication: 31 July 2020.

${ }^{\circ}$ Copyright: the Author(s), 2020

Licensee PAGEPress, Italy

Monaldi Archives for Chest Disease 2020; 90:1424

doi: 10.4081/monaldi.2020.1424

This article is distributed under the terms of the Creative Commons Attribution Noncommercial License (by-nc 4.0) which permits any noncommercial use, distribution, and reproduction in any medium, provided the original author(s) and source are credited. ease (COVID-19) pandemic as noted by Centres for Disease Control and Prevention (CDC) [1]. These patients are more prone for intensive care admission with ventilator requirement when infected with SARS-Cov-2 due to acute respiratory syndrome [2].

COPD exacerbations are events associated with increased airway inflammation and significant gas trapping. They are important in management of COPD as they negatively impact health status of a patient and disease progression. WHO and CDC current guidelines for COVID-19 treatment do not cover COPD specifically. Treatment of COPD severe exacerbations especially those with acute respiratory failure needs treatment with oxygen and pharmacological agents along with supporting the patient's ventilation to decrease work of breathing. These treatment options involve aerosol generating procedures like nebulization and ventilation support using non-invasive ventilation (NIV) and high flow nasal cannula (HFNC). Due to increased risk of severe acute respiratory syndrome coronavirus 2 (SARS-Cov-2) transmission, their usage even with standard contact and airborne precautions during this COVID-19 pandemic is not encouraged [3]. Analysis of available data about the risks of usage of these two treatment options in acute exacerbation of COPD (AECOPD) during COVID-19 pandemic is limited.

\section{Nebulization therapy for severe AECOPD during COVID 19 pandemic}

Three classes of medications commonly used in severe AECOPD are bronchodilators, steroids, and antibiotics. Among these, inhaled short acting bronchodilators are the mainstay of therapy. Due to more reliable drug delivery to the airway, in severe AECOPD nebulized form of therapy for this medication is preferred [4]. In a country like India, this is important because studies have shown that inhaler technique for both metered dose inhaler and dry powder inhaler among COPD patients is both clinically and statistically significantly poor [5]. One study has even shown that among stable COPD patients, when handling and inhalation techniques for different inhalation devices were compared, minimum errors were seen in nebulizer users [6]. When such patients come to emergency with severe AECOPD, use of inhalation devices other than nebulizers for bronchodilator administration can be catastrophic. Evidence showing nebulizer therapy as an aerosol-generating procedure causing transmission of COVID-19 is limited. A study during the 2002-2003 SARS-CoV outbreak had showed no significant evidence of SARS-CoV virus specific material in air samples taken $30 \mathrm{~cm}$ above patient's head after 
large volume nebulization therapy [7]. A 2012 systemic review showed statistically insignificant risk of SARS-CoV transmission among health care workers treating patients having nebulizer treatment [8]. It is difficult to conclude whether risk of transmission of SARS-CoV-2 during nebulized therapy is because of increased contact between personal giving treatment and patient or due to nebulization per se [9]. Aerosol generated during nebulizer treatment is not patient-derived. Its generated from nebulizer chamber fluid and hence does patient-derived viral particles is not carried by them [10]. Nebulizers when used in critical ill requiring ventilator support requires the circuit to be intact to prevent virus transmission. This is possible with mesh nebulizers as they stay in line for a longer time and have reservoir design allowing to use medication without breaking the circuit [11]. In hospitals when using nebulizers disposing off used equipment after each use and maintaining at least 6 feet or greater distance from the patient is advised. Steroids and systemic antibiotics are to be given as per routine recommendations.

\section{Non-invasive modalities for ventilation support in severe AECOPD during COVID 19 situation: NIV and HFNC}

For ventilator support in a severe AECOPD, NIV in bilevel mode is the preferred modality. Indications for NIV should be as per recent GOLD guidelines. It can be delivered preferably via a standard ventilator with dual limb circuit or via bed side portable ventilator. As it is considered an aerosol generating procedure, proper airborne precautions to be used during the NIV usage. Dispersion of expired air causing cross transmission when using bilevel NIV in fact depends on the interface used. NIV machine with dual limb through helmet interface with viral filter on expiratory circuit is preferred with a tight seal at neck helmet interface. According to some studies, leakage of exhaled air is negligible in this method [12]. As an alternative if this is not available, single limb circuit NIV with non-vented mask and exhalation port in the circuit can be used provided the ventilation mode used supports the option of non-vented masks and exhalation port. A viral filter between mask and exhalation port should be used and an external humidifier use is discouraged. Oxygen should be at the patient end when routed into the circuit [13]. Mask size that fits best to be used. Minimum pressure adjusted to patients work of breathing and arterial blood gas tensions to be used as higher inspiratory pressures increase droplet dispersion [10]. NIV posing as risk factor for infection transmission during a pandemic is based on the study of particle dispersion using experimental models where NIV was performed after filling a mannequin lung with smoke [14]. There is lack of data showing comparison of particle dispersion between individuals getting NIV or not and there are no human studies evaluating particle dispersion during NIV use. In fact, NIV mask in turn may offer protection from secretions of the infected patient when coughing or speaking [15].

HFNC is also one of the noninvasive modalities commonly being used nowadays for AECOPD especially in those having mask intolerance. Recent systemic review of HFNC use in AECOPD has shown that this modality reduces work of breathing similar to NIV and is in fact more comfortable to patients [16]. Like NIV use during COVID-19 pandemic, there is a concern of increased bio-aerosol dispersion during HFNC use due to usage of high gas flow. Laboratory studies using smoke simulation methods in manikin have shown that with HFNC, exhaled air mean distance can be up to 172 $\mathrm{mm}$ at $60 \mathrm{l} / \mathrm{min}$ flow which is similar to that seen with a simple oxygen mask at $15 \mathrm{l} / \mathrm{min}$ [17]. These risks can be further decreased by using simple surgical face masks over cannula at the flow rate of 40 $1 /$ min but at the expense of little $\mathrm{CO}_{2}$ retention [18].

\section{Health care workers protection during AECOPD care during COVID-19 situation}

Personal protective equipment (PPE) usage for health care workers when treating AECOPD patients during this COVID-19 pandemic should be as per WHO guidelines which includes a respirator, gown gloves, eye protection, apron, and hand hygiene [19]. Ideally these patients should be treated in an airborne infection isolation room (single relative negative pressure patient rooms with air changes of at least 6/hour) and if such rooms are unavailable, a portable high efficiency particulate air (HEPA) unit should be used in the room. Masks like filtering facepiece respirator (FFR) are preferred over simple medical masks because they are tight fitting and provide inward protection to upper airways of the wearer from airborne droplet nuclei due to their filtering media. Filtering facepiece 2 (FFP2, N95 equivalent) is the minimum recommended respirator as they have filtering performance of at least $94 \%$. Before every use respirator seal check should be performed each time. These masks should be ideally removed in the end just before removing the gloves. Regular training to remove PPE properly should be part of the training process to avoid self-contamination of health care workers due to its improper removal [20].

In summary, during care of a COVID-19 patient, any respiratory therapy has a risk of aerosol generation. Severe AECOPD during pandemics should be managed with nebulization and ventilation support tailored to the patient needs like to non-pandemic situations with only some unique modifications. Airborne precautions along with standard contact precautions should be primary concern when treating such patients.

\section{References}

1. CDC. Coronavirus Disease 2019 (COVID-19). Centers for Disease Control and Prevention. 2020. Accessed: 1 June 2020. Available from: https:/www.cdc.gov/coronavirus/2019-ncov/ covid-data/investigations-discovery/assessing-risk-factors.html

2. Guan WJ, Liang WH, Zhao Y, et al. Comorbidity and its impact on 1590 patients with COVID-19 in China: a nationwide analysis. Eur Respir J 2020;55:2000547. doi: 10.1183/ 13993003.00547-2020.

3. WHO. Clinical management of COVID-19: interim guidance, 27 May 2020. World Health Organization, Geneva; 2020.

4. Patel AR, Patel AR, Singh S, et al. Global initiative for chronic obstructive lung disease: The changes made. Cureus 2019;11:e4985. doi: 10.7759/cureus.4985

5. Suthar J, Patel ZA, Shelat B, et al. Assessment of inhalation techniques in COPD and asthma patients using metered dose inhaler and rota-haler. Indian J Pharm Pract 2019;12:217.

6. Arora P, Kumar L, Vohra V, et al. Evaluating the technique of using inhalation device in COPD and bronchial asthma patients. Respir Med 2014;108:992-8. doi: 10.1016/ j.rmed.2014.04.021 
7. Wan GH, Tsai YH, Wu YK, Tsao KC. A large-volume nebulizer would not be an infectious source for severe acute respiratory syndrome. Infect Control Hosp Epidemiol 2004;25:1113-5. doi: 10.1086/502353

8. Tran K, Cimon K, Severn M, et al. Aerosol generating procedures and risk of transmission of acute respiratory infections to healthcare workers: a systematic review. PLoS One 2012;7:e35797. doi: 10.1371/journal.pone.0035797.

9. CDC. Coronavirus Disease 2019 (COVID-19). Centers for Disease Control and Prevention. 2020. Accessed: 1 June 2020. Available from: https:/www.cdc.gov/coronavirus/2019ncov/hcp/infection-control-faq.html

10. GOV.UK [Internet]. New and Emerging Respiratory Virus Threats Advisory Group. Accessed: 1 June 2020. Available from: https://www.gov.uk/government/groups/new-andemerging-respiratory-virus-threats-advisory-group

11. Ari A, Atalay OT, Harwood R, et al. Influence of nebulizer type, position, and bias flow on aerosol drug delivery in simulated pediatric and adult lung models during mechanical ventilation. Respir Care 2010;55:845-51.

12. Hui DS, Chow BK, Lo T, et al. Exhaled air dispersion during noninvasive ventilation via helmets and a total facemask. Chest 2015;147:1336-43. doi: 10.1378/chest.14-1934.

13. British Thoracic Society [Internet]. COVID-19: information for the respiratory community. Accessed: 30 July 2020. Available from: https://www.brit-thoracic.org.uk/aboutus/covid-19-information-for-the-respiratory-community/

14. Hui DS, Chow BK, Ng SS, et al. Exhaled air dispersion dis- tances during noninvasive ventilation via different Respironics face masks. Chest 2009;136:998-1005. doi: 10.1378/chest.090434.

15. Yam LYC, Chan AYF, Cheung TMT, et al. Non-invasive versus invasive mechanical ventilation for respiratory failure in severe acute respiratory syndrome. Chin Med J (Engl) 2005; 118:1413-21.

16. Pisani L, Astuto M, Prediletto I, Longhini F. High flow through nasal cannula in exacerbated COPD patients: a systematic review. Pulmonology 2019;25:348-54. doi:10.1016/j.pulmoe.2019.08.001

17. Hui DS, Chow BK, Lo T, et al. Exhaled air dispersion during high-flow nasal cannula therapy versus CPAP via different masks. Eur Respir J 2019;53:1802339. doi: 10.1183/ 13993003.02339-2018.

18. Leonard S, Atwood CW Jr, Walsh BK, et al. Preliminary findings on control of dispersion of aerosols and droplets during highvelocity nasal insufflation therapy using a simple surgical mask: Implications for the high-flow nasal cannula. Chest 2020:S00123692(20)30579-1. doi: 10.1016/j.chest.2020.03.043.

19. WHO. Rational use of personal protective equipment for coronavirus disease (COVID-19) and considerations during severe shortages: interim guidance, 6 April 2020. World Health Organization, Geneva; 2020.

20. Ippolito M, Vitale F, Accurso G, et al. Medical masks and respirators for the protection of healthcare workers from SARSCoV-2 and other viruses. Pulmonology 2020;26:204-12. doi: 10.1016/j.pulmoe.2020.04.009. 